\title{
Analysis of the penstock for pit turbine using computational fluid dynamics
}

\author{
Amit Anakiya ${ }^{1}$, Hiren Prajapati $^{2}$, Sunil Prajapati ${ }^{3}$ \\ ${ }^{I}$ (PG Student, U.V.PATEL College of Engineering, Ganpat University, Kherva, Mehsana, \\ ${ }^{2}$ (Professor, U.V.PATEL College of Engineering, Ganpat University, Kherva, Mehsana) \\ ${ }^{3}$ (Director, ESC Works Pvt. Ltd. Ahmedabad)
}

\begin{abstract}
The whole work of the paper is covered by the modeling modification for the CFD analysis, qualitative meshing, selection of the turbulence model, CFD analysis. More time in the CFD analysis is occupied by the modeling of the component and its meshing. Penstock for the pit turbine is different from the other penstock because it has water distribution chamber which spits the water from the main penstock. Because of the turbulence flows the actual pressure on the inner wall of the penstock cannot easily predicted by the analytical method. This paper focuses on to find the pressure on the inner wall.
\end{abstract}

Keywords: Pit turbine, $k$-e model, Solid Works 14, ANSYS Fluent 14.5.

\section{Introduction}

The world's hydro power potential amounts to 20 billion Mega Watt hours per year and only 30 percent of this has been developed so far. There are numbers of the components in the hydro power plant like source, penstock, turbine, generator etc. The penstock is the long pipe that carries the water flowing from the reservoir towards the power generation unit, comprised of the turbines and generator. The water in the penstock possesses kinetic energy due to its motion and potential energy due to its height. The total amount of power generated in the hydroelectric power plant depends on the height of the water reservoir and the amount of water flowing through the penstock [1]. Hence it becomes extremely important that water is brought with minimum head loss from the source to the inlet of the turbine. This ensures higher hydraulic efficiency of the overall plant and structural safety. In this case pit turbine is use to produce the power. The net head of the power plant is $25 \mathrm{~m}$. The water flow in the main penstock is split in the turbine penstock. The water exerts the high pressure on the inner wall of the turbine penstock. The external wall is covered with the concrete. The overall arrangement is shown in Fig. 1.

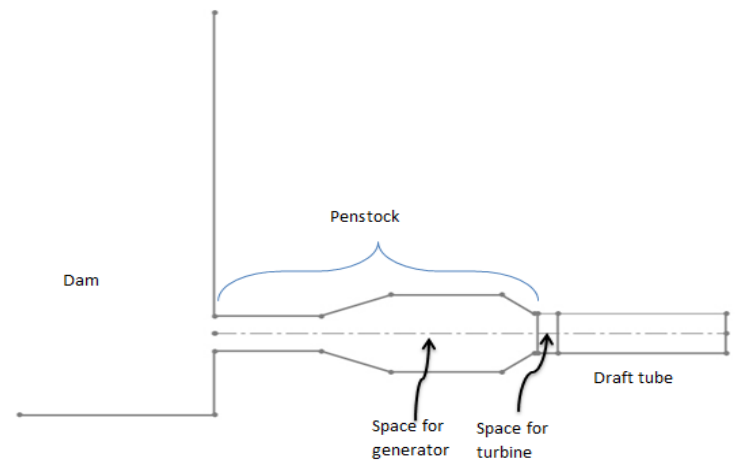

Fig.1 Modeling of the penstock

\section{Literature Review}

Adam Adamkowski presents the case study on the LAPINO power plant (Poland) penstock failure in journal of hydraulic engineering. The paper presents the results of investigations carried out in connection with a penstock rupture at a small hydropower plant in Poland. The investigations are consist of material tests of the ruptured penstock shell, analysis of the stress in the shell, analysis of hydraulic transients under conditions of failure, and testing of the penstock and generator sets after repair. In the case under consideration, excessive water hammer caused by rapid flow cut-off was recognized as the direct cause of the penstock burst. Low strength of the penstock shell because of low quality weld joints and lack of strengthening in places of large stress concentration also contributed to the penstock failure [6]. Adamkowski, L. Kwapisz presents the 'strength analysis of penstock bifurcation in hydropower a plant' in the present paper. The analysis consists of determining the maximal internal pressure, stress analysis of the pipeline shell for assumed loading and assumed or determined material properties. The investigation results can be helpful when determining the proper rate of 
the flow cut-off and recommending the strengthening precautions to be applied in places of maximum stress concentration in order to prevent future penstock ruptures. Good coincidence of experimental and numerical results has been confirmed [7]. RK Malik, Paras Paudel present 3D flow modeling of the trifurcation. The foremost objective of the study was to find out the most efficient profile of trifurcation in given constraints of pressure, velocity and layout of the overall geometry [8]. E. Casartelli and N. Ledergerber present the paper which shows the aspects of the numerical simulation for the flow in penstocks. The flow in a full-scale penstock has been computed. Characteristic of this flow is the very high Reynolds-number, which ranges from up to 100 million. The results show that for the numerical simulations special care has to be applied to mesh, boundary conditions, turbulence models and numeric [9].

\section{Parameters Of The Existing Penstock}

Structural steel A36 is widely used in penstock. The major parameters are shown in the table 1.

Table 1 Major Parameter

\begin{tabular}{|c|c|c|}
\hline Sr no & Parameter & Value \\
\hline 1 & Available head & $25 \mathrm{~m}$ \\
\hline 2 & Material for the penstock & Structural steel-A36 \\
\hline 3 & Friction factor of structural steel & 0.45 \\
\hline
\end{tabular}

IV. Modeling of the existing penstock

The modeling was carried out on solid works 2014

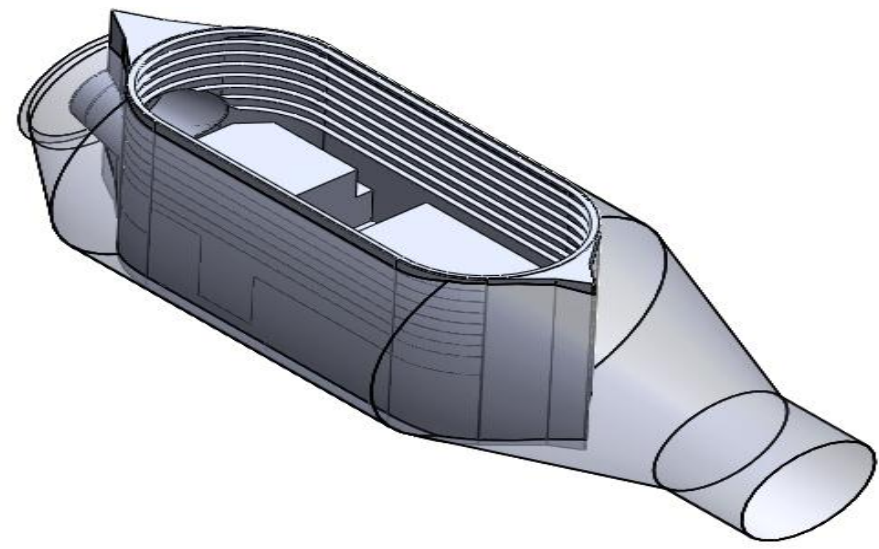

Fig.2 Modeling of the penstock

\section{Fluid Analysis By Analytical Method}

In the following calculations pressure at the inlet and the outlet of the penstock is calculated. These calculations are based on the assumption listed below.

Input data: Total Height $\quad=25 \mathrm{~m}$

Pipe diameter $\quad=2.730 \mathrm{~m}$ (Outer diameter)

Thickness of the penstock $=16 \mathrm{~mm}$

Material $\quad=$ Structural steel A36

Assumptions for analytical calculation

1. Penstock diameter $2.73 \mathrm{~m}$ throughout

[A] Pressure at the inlet of the penstock

Where

$$
\mathbf{p}=\boldsymbol{\rho g H}
$$

$\boldsymbol{\rho}=$ Density of water $\left(1000 \mathrm{~kg} / \mathrm{m}^{3}\right)$

$\mathrm{g}=$ Gravitational acceleration $\left(9.81 \mathrm{~m} / \mathrm{s}^{2}\right)$

$\mathrm{H}=$ Total head at inlet

$$
\begin{aligned}
& =1000 \times 9.81 \times 25 \\
& =2,45,250 \mathrm{~N} / \mathrm{m}^{2}
\end{aligned}
$$

[B] Pressure at the inlet of the turbine[2]

Here the pressure is

Where

$$
\mathbf{p}=\rho g H_{\text {net }}
$$

$\mathbf{H}_{\text {net }}=$ Net head at inlet 
Now,

Where

$$
\mathbf{H}_{\mathrm{Net}}=\mathbf{H}-\mathbf{H}_{\mathbf{f}}-\mathbf{H b}
$$

$\mathrm{H}=$ Total head or gross head

$\mathbf{H}_{\mathbf{f}}=$ Head loss due to friction

$\mathbf{H b}=$ Head loss due to bend

There is no bend in the penstock $\mathbf{H b}=0 \mathrm{~m}$.

Head loss due to friction at the inlet of the turbine

[For laminar flow]

Frictional factor [2]

$\mathrm{f}=$ Frictional factor $=\frac{\mathbf{6 4}}{\mathrm{R}_{\mathrm{e}}}=\frac{\mathbf{6 4}}{\mathbf{6 0} \times \mathbf{1 0 ^ { 6 }}}=1.066 \times 10-6$

Length of the pipe connected to the water source from the design $=7 \mathrm{~m}$

Total length of the penstock $\mathrm{L}=16.252+7=23.252 \mathrm{~m}$

Now head loss due to friction

So net head from equation 2

$$
\begin{aligned}
\mathbf{H}_{\mathrm{f}} & =\mathbf{f} \frac{\mathrm{L}}{\mathrm{D}} \frac{\mathrm{V}^{2}{ }_{\text {avg }}}{2 \mathrm{~g}} \\
& =1.066 \times 10^{-6} \times \frac{23.252}{2.714} \times \frac{22.1472^{2}}{2 \times 9.81} \\
& =2.269 \times 10^{-4} \mathrm{~m}
\end{aligned}
$$

$$
\begin{aligned}
\mathbf{H}_{\text {Net }} & =25-0.000269 \\
& =24.999731=25 \mathrm{~m}
\end{aligned}
$$

[For turbulent flow]

Roughness of the pipe $\varepsilon=45 \times 10-6 \mathrm{~m}$

Relative roughness $=\frac{\varepsilon}{D_{\mathrm{H}}}=\frac{45 \times 10^{-6}}{2.714}=0.0000166$

From moody diagram: Friction factor $\mathbf{f}=\mathbf{0 . 0 1 0 5}$

So,

So net head from equation 2

$$
\begin{aligned}
H_{f} & =f \frac{L}{D} \frac{V^{2}{ }_{a v g}}{2 g} \\
& =0.0105 \times \frac{23.252}{2.714} \times \frac{22.1472^{2}}{2 \times 9.81} \\
& =2.26 \mathrm{~m}
\end{aligned}
$$

$$
\mathbf{H}_{\mathrm{Net}}=25-2.3
$$

Here for the laminar flow net head remain same with gross head (equation 3) but in the turbulent flow is change (equation 4).

So the pressure at the inlet of the turbine

$$
\begin{aligned}
\mathbf{p} & =\rho g H_{\mathrm{Net}} \\
& =1000 \times 9.81 \times 22.74 \\
& =2,23,079 \mathrm{~N} / \mathrm{m}^{2}
\end{aligned}
$$

It is clear from the equation 2 and equation 5 that pressure drop at the inlet of the turbine $=$ $2,45,250-2,23,079=22,171 \mathrm{~N} / \mathrm{m}^{2}$

It is possible to calculate the pressure at different distance in the penstock. The generated graph by using equation 4 and 5 is shown below at different distance. 


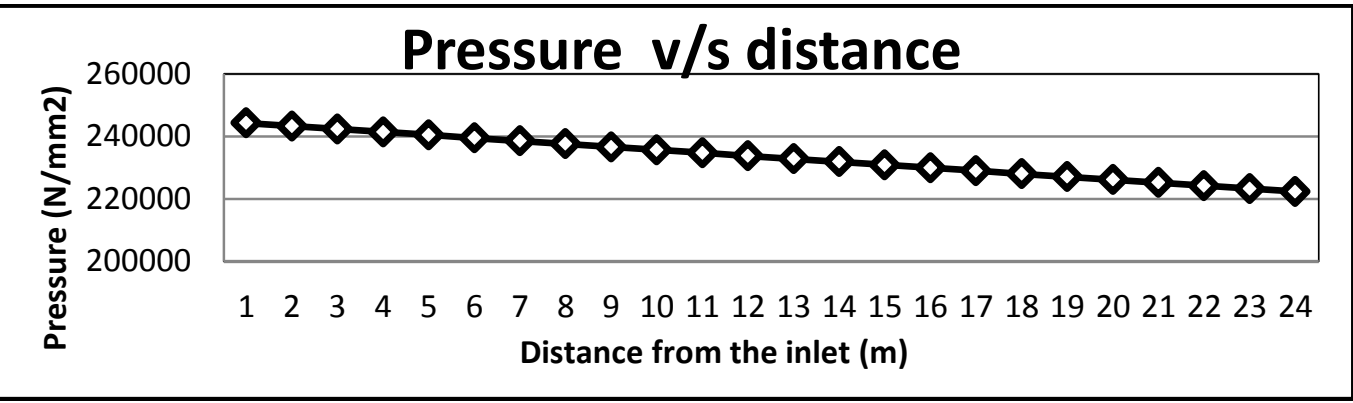

Fig. 3 Graph of pressure v/s distance from the inlet

VI. Prerequisites For The CFD Analysis

CFD analysis is start with preparing the model. Create the model that only has wet surfaces. Logic behind that is to decrease the computational power use for the analysis. So that complex geometry can be analyzed in with simple computer. And the pipe is extended same as the entrance region of the penstock. Reason to extend the pipe in outlet is to get the value near to the actual scenario. Create new surfaces where data of analyses is required.

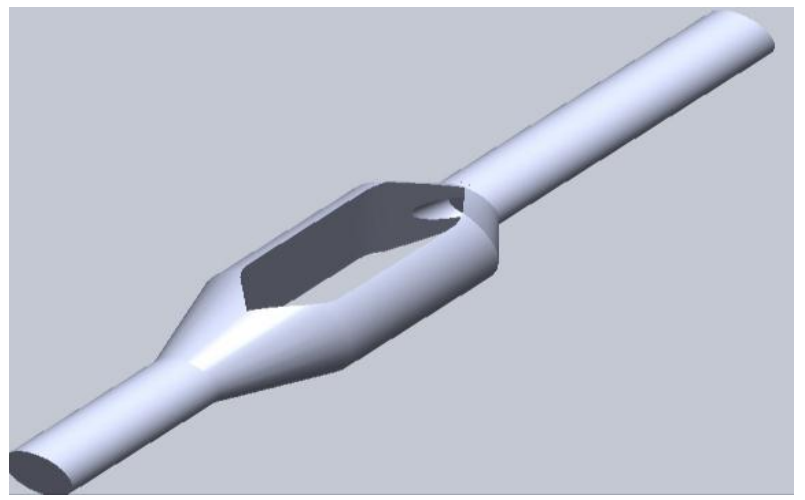

Fig. 4 Model with only wet surfaces

VII. Meshing

Meshing of the model is done by the ANSYS ICEM. Element shape for the surface is triangle and for the fluid volume tetrahedron is used. Now the pressure gradient is higher near the wall so it requires precise meshing. It is done by the prism mesh near the wall. To select the size of the prism mesh following are the calculations.

\section{Meshing on the surface and the internal volume}

Create triangle mesh on all surfaces of the geometry with the size of $100 \mathrm{~mm}$ and then create the tetrahedral mesh on the all internal volume of the geometry with size of $300 \mathrm{~mm}$. After computing the all mesh numbers of tri mesh are TETRA: 10, 18,177 and TRI: 1, 30,912.

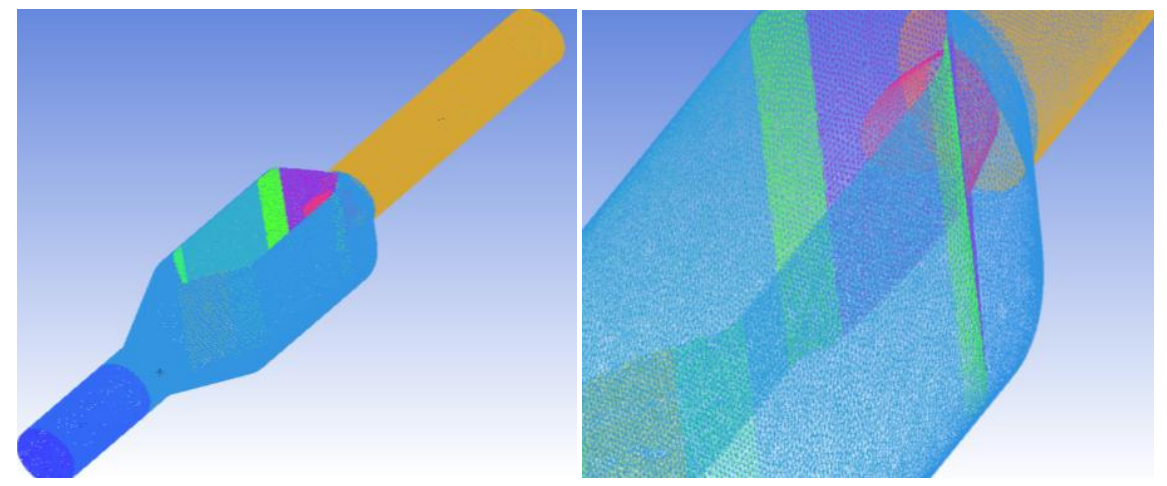

Fig. 5 Meshing of model with triangle and tetrahedral elements 


\section{Velocity at inlet $\mathbf{V}[2]$}

From Bernoulli's equation

Average velocity

Where $\mathrm{z}=$ Available head

$$
\mathrm{V}=\sqrt{2 \mathrm{gz}}
$$

$$
\begin{aligned}
& =\sqrt{2 \times 9.81 \times 25} \\
& =22.1472 \mathrm{~m} / \mathrm{s}^{2}
\end{aligned}
$$

\section{Hydraulic diameter [2]}

For the circular pipe,

Wetted perimeter $\mathrm{P}=2 \pi \mathrm{r}$

$$
D_{H}=\frac{4 A}{P}=\frac{4 X \pi r^{2}}{2 \pi r}
$$

Where $\mathrm{r}=$ inner radius

\section{Reynold's number Re [2]}

$$
\mathrm{D}_{\mathrm{H}}=2 \mathrm{r}=\mathrm{D}=2.698 \mathrm{~m}
$$

Where $\mathrm{V}=$ Velocity

$$
\operatorname{Re}=\frac{\rho V D}{\mu}
$$

$\mathrm{D}=$ Hydraulic diameter of penstock at inlet

$\mu=$ Dynamic viscosity $(1.002 \times 10-3 \mathrm{~N} * \mathrm{~S} / \mathrm{m} 2)$

$$
\begin{aligned}
& =\frac{1000 \times 22.1472 \times 2.714}{1.002 \times 0.001} \\
& =60 \times 10^{6}
\end{aligned}
$$

Calculation for the grid spacing [3]

$$
\begin{aligned}
\Delta \mathrm{y} & =\frac{\mathrm{y}^{+} \times \mathrm{D}}{0.172 \times \mathrm{Re}^{0.9}} \\
& =\frac{50 \times 2.73}{0.172 \times 60000000^{0.9}} \\
& =0.0727 \mathrm{~mm}
\end{aligned}
$$

With help of this grid space prism mesh for the 5 layer on the near the walls is created.
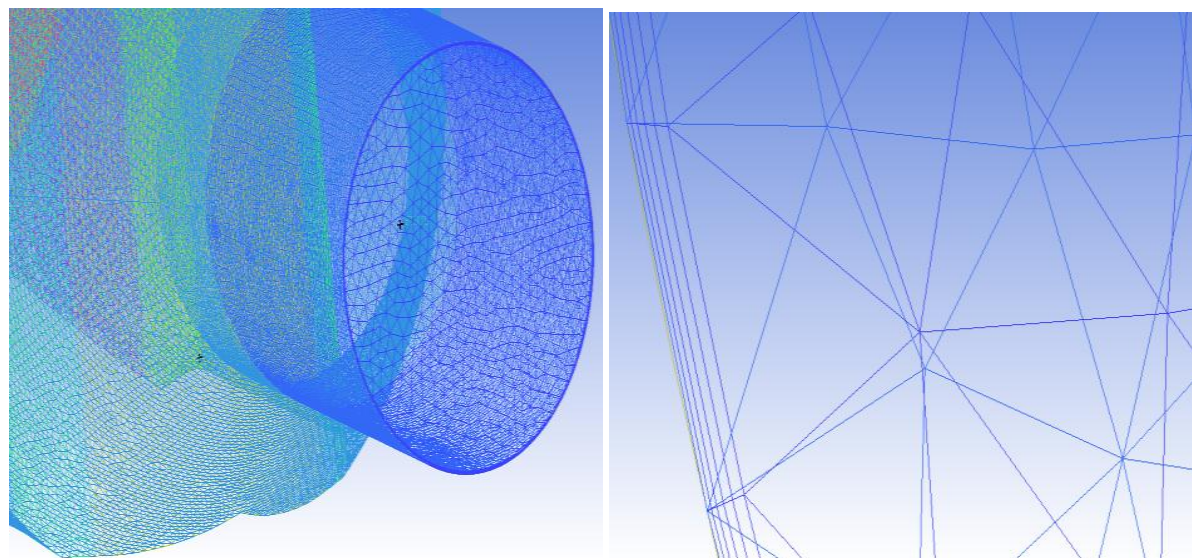

Fig. 6 Meshing of model with triangle, tetrahedral and prism elements

Create prism mesh near the wall surface. After computing the all mesh, the numbers of prism mesh are 64,366.

\section{Simulation}

Analysis carried out by the ANSYS Fluent 14. As per the calculated Reynolds number, it indicates that flow is turbulent. There are numbers of turbulence model available for the analysis. In this case K-epsilon (2 equation) is selected it is as per the paper [4]. According to this paper the $\mathrm{K}$-epsilon model can give a good prediction for the mean velocities and the static pressure field. And because of the low eddy generation in the flow standard wall treatment is selected.

Properties of the fluid (Water) 
Table 2 properties of the fluid

\begin{tabular}{|c|c|}
\hline Property & Value \\
\hline Density & $1000 \mathrm{Kg} / \mathrm{m} 3$ \\
\hline Kinematic Viscosity & $1.002 \mathrm{~kg} / \mathrm{m}^{*} \mathrm{~s}$ \\
\hline
\end{tabular}

Table 3 Boundary conditions

\begin{tabular}{|l|l|l|}
\hline Part & Operating parameter & Value \\
\hline \multirow{2}{*}{ Inlet } & Velocity & $22 \mathrm{~m} / \mathrm{s}$ \\
\cline { 2 - 3 } & Hydraulic diameter & $2730 \mathrm{~mm}$ \\
\hline Wall & Friction factor & $0.45 \mu \mathrm{m}[5]$ \\
\hline Outlet & Out flow & 1 \\
\hline
\end{tabular}

\section{Post processing}

After the calculation it needs to interpret the result as per requirement. In this case the required data is the pressure on the inner. This pressure is used for the FEA analysis.

Pressure on the parts of penstock

Pressure on plan at middle section

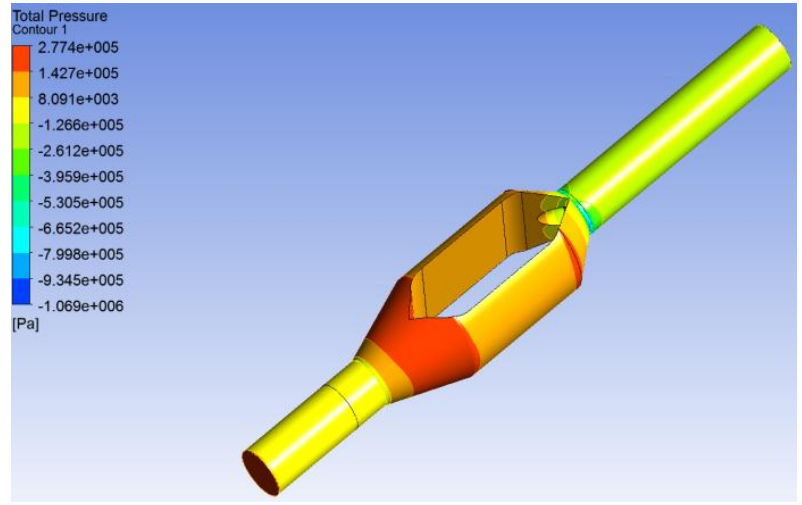

Fig. 7 Pressure on the parts of penstock

At it is easy to get idea of the pressure by creating plane at middle section of the penstock

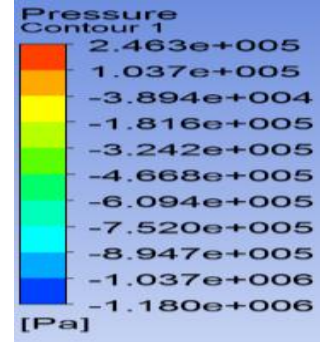

\section{Area weighted total pressure}

Fig. 8 Pressure on plan at middle section

Table 4 Area weighted total pressure

\begin{tabular}{|c|c|}
\hline Parts & Pressure (Pascal) \\
\hline Ext inlet wall & 127137.44 \\
\hline Ext outlet wall & -72613.078 \\
\hline Inlet & 241803.33 \\
\hline Inner wall & 156401.78 \\
\hline Inner wall inlet cone & 225241.86 \\
\hline Inner wall inlet cone side & 180844.47 \\
\hline Inner wall outlet cone & 99561.773 \\
\hline Inner wall outlet cone side & 131268.16 \\
\hline Outer wall & 145139.13 \\
\hline Outlet & 75172.531 \\
\hline Outlet small cone & 104397.9 \\
\hline Outlet small cone plate & -301486.53 \\
\hline
\end{tabular}


Now actual problem is failure in the inner wall. So the area weighted average total pressure on inner wall is

Table 5 Area weighted total pressure on inner wall

\begin{tabular}{|c|c|}
\hline Parts & Pressure (Pascal) \\
\hline Inner wall & 156401.78 \\
\hline Inner wall outlet cone side & 131268.16 \\
\hline Inner wall inlet cone side & 180844.47 \\
\hline $\begin{array}{c}\text { Area weighted total pressure on parts } \\
\text { under action of pressure of the water }\end{array}$ & $\mathbf{1 5 6 1 7 1 . 4 7 ~ N / m 2}$ \\
\hline
\end{tabular}

\section{Conclusion}

According to the CFD analysis, area weighted pressure on the inner wall is $156171.41 \mathrm{pa}=0.1562$ $\mathrm{N} / \mathrm{mm} 2$. This analysis includes turbulent analysis, so the pressure is reduce due to turbulence effect. Now this pressure is use for the static structural analysis.

\section{References}

[1]. Module 5: Hydropower engineering, Version 2, IIT Kharagpur

[2]. Yusus cengel, 'Fluid mechanics fundamental and application' -book

[3]. Cheng-Wen Lin 1, Scott Percival 1, and Eugene H. Gotimer,' viscous drag calculations for ship hull geometry'

[4]. C.X. Zhange, 'Numerical prediction of the turbulent recirculating flows with k-e model', journal of wind engineering and industrial aerodynamic, volume- 51 issue-2, feb-1994.

[5]. Pipe Roughness Values, Jacques Chaurette P. engineering, www.lightmypump.com February 2003

[6]. Adam Adamkwoski, 'Case study on Lapino power plant failure' journal of hydraulic engineering, 2001

[7]. Adamkowski \& L. Kwapisz, 'the strength analysis of penstock bifurcation', Institute of the fluid flow machinery

[8]. R.K. Malik, Paras Paudel present 3D flow modeling of the first trifurcation made in the Nepal, Hydro Nepal , issue 5,2009

[9]. E. Casartelli N. Ledergerber 'Aspects of the numerical simulation for the flow in penstocks', IGHEM-2010, Oct. 21-23, 2010, AHEC,IIT Roorkee ,India 